\title{
Differentiation of European cattle by AFLP fingerprinting
}

\author{
R. Negrini ${ }^{1, *}$, I. J. Nijman ${ }^{1,+}$, E. Milanesi* ${ }^{*}$ K. Moazami-Goudarzi ${ }^{\ddagger}$, J. L. Williams ${ }^{2, \S}$, G. Erhardt ${ }^{\natural}$, \\ S. Dunner $^{* *}$, C. Rodellar ${ }^{\dagger+}$, A. Valentini ${ }^{\ddagger \neq}$, D. G. Bradley ${ }^{\S \S}$, I. Olsaker ${ }^{\natural \uparrow l}$, J. Kantanen ${ }^{* * *}$, \\ P. Ajmone-Marsan*, J. A. Lenstra ${ }^{\dagger}$ and the European Cattle Genetic Diversity Consortium ${ }^{3}$
}

*Institute of Zootechnics, Catholic University of Sacred Heart, Piacenza, Italy. ${ }^{\dagger}$ Faculty of Veterinary Medicine, Utrecht University, Utrecht, The Netherlands. ' Laboratoire de Génétique Biochimique et de Cytogénétique, INRA, Jouy-en-Josas, France. ${ }^{\S}$ Roslin Institute, Midlothia, UK. "Justus-Liebig Universität, Giessen, Germany. ${ }^{* *}$ Universidad Complutense de Madrid, Spain. ${ }^{+\dagger}$ Veterinary Faculty, Zaragoza, Spain.

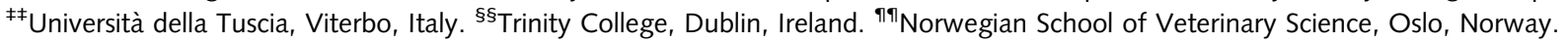

${ }^{* * *}$ Agrifood Research Finland (MTT), Jokioinen, Finland

\section{Summary}

\begin{abstract}
The Neolithic introduction of domestic cattle into Europe was followed by differential adaptation, selection, migration and genetic isolation, leading ultimately to the emergence of specialized breeds. We have studied the differentiation of European cattle by amplified fragment length polymorphism (AFLP) fingerprinting. Combining AFLP data sets from two laboratories yielded 81 biallelic polymorphic markers scored in 19-22 individual animals from 51 breeds. Model-based clustering differentiated Podolian cattle as well as French and Alpine breeds from other European cattle. AFLP genetic distances correlated well with microsatellite-based genetic distances calculated for the same breeds. However, the AFLP data emphasized the divergence of taurine and indicine cattle relative to the variation among European breeds and indicated an Eastern influence on Italian and Hungarian Podolian breeds. This probably reflects import from the East after the original introduction of domestic cattle into Europe. Our data suggest that Italian cattle breeds are relatively diverse at the DNA sequence level.
\end{abstract}

Keywords amplified fragment length polymorphism, cattle, genetic diversity, introgression, zebu.

\section{Introduction}

Genetic differentiation of animal breeds has been compared at the DNA level using genetic markers. These studies have revealed the genetic complexity of the domestication process, migration routes and relationships among current breeds (Hanotte et al. 2002; Bruford et al. 2003; Cymbron et al. 2005; Beja-Pereira et al. 2006; Freeman et al. 2006). DNA analysis may elucidate the

Address for correspondence

J.A. Lenstra, Faculty of Veterinary Medicine, Utrecht University, Yalelaan 2, 3584 CM Utrecht, The Netherlands.

E-mail J.A.Lenstra@vet.uu.nl

Accepted for publication 14 November 2006

${ }^{1}$ These authors contributed equally to this work

${ }^{2}$ Present address: Parco Tecnologico Padano, Via Einstein, 26900 Lodi, Italy.

${ }^{3}$ See Appendix 1 molecular background of the phenotypic variation among breeds and suggest priorities for conservation (Ruane 1999; Hall 2004).

Analyses of mitochondrial DNA and microsatellite loci have indicated that taurine and zebu cattle were domesticated independently (Bradley et al. 1996) and that many of the African and Middle-Eastern breeds are of mixed origin (Moazami-Goudarzi et al. 2001; Hanotte et al. 2002; Kumar et al. 2003; Freeman et al. 2004; Ibeagha-Awemu et al. 2004). Selective breeding and genetic isolation of taurine European cattle has resulted in many specialized dairy and beef breeds, several of which are now used worldwide. Allele frequencies of microsatellite markers reveal a genetic differentiation of breeds (e.g., see MacHugh et al. 1997; Moazami-Goudarzi et al. 1997; Peelman et al. 1998; Martín-Burriel et al. 1999; Schmid et al. 1999; Kantanen et al. 2000; Cañón et al. 2001; Del Bo et al. 2001; Wiener et al. 2004; Cymbron et al. 2005). However, the breeds in the data sets reported so far represent only partially the diversity of European cattle. 
Amplified fragment length polymorphism (AFLP) fingerprinting detects variation that corresponds to SNPs and indels and is informative for genetic diversity (Bensch \& Åkesson 2005; Foulley et al. 2006; SanCristobal et al. 2006). Ajmone-Marsan et al. (2002) and Negrini et al. (2006) demonstrated the use of AFLP fingerprinting for estimation of genetic distances within and across cattle breeds. Here we analyze 47 European breeds, one African breed and three Indian zebu breeds in order to study the genetic differentiation of cattle across Europe.

\section{Material and methods}

\section{Animals}

DNA was isolated using standard procedures from blood or sperm samples. Collection of European (European Cattle Genetic Diversity Consortium 2006, Fig. 1), African (Moazami-Goudarzi et al. 2001) and Asian (Bradley et al. 1994; Loftus et al. 1994) cattle was described previously. Other breeds were sampled in Italy, including Holstein-Friesian and Limousin cattle. Microsatellite as well as AFLP genotypes

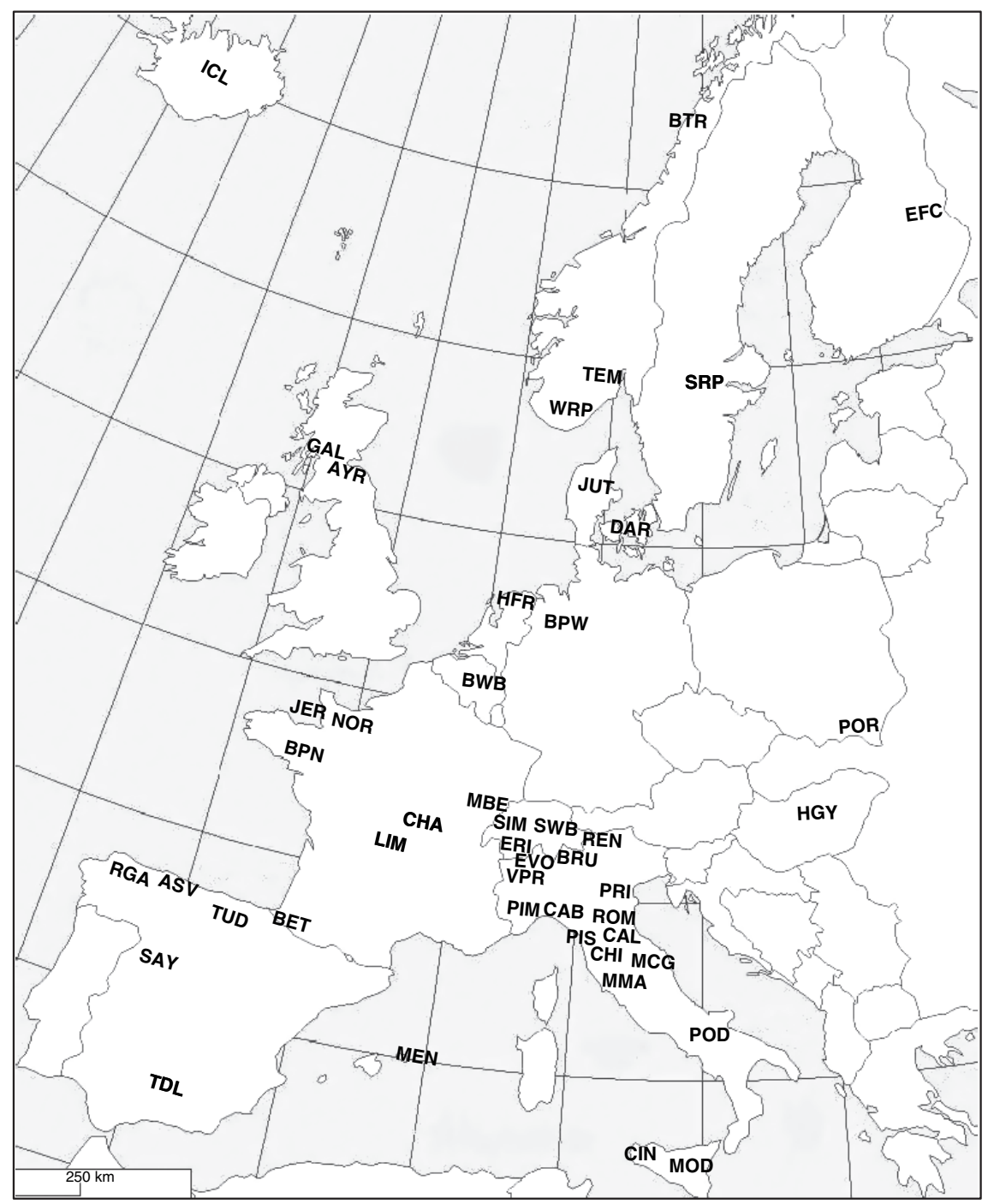

Figure 1 Origin of European breeds sampled in this study. ASV, Asturiana de los Valles; AYR, Ayrshire; BET, Betizu; BPW; German Black-Pied Western Reserve; BPN, Bretonne Pie Noire; BRU, Bruna Alpina; BTR, Blacksided Troender and Nordland; BWB, Belgian White-Blue; CAB, Cabannina; CAL, Calvana; CHA, Charolais; CHI, Chianina; CIN, Cinisara; DAR, Danish Red; EFC, Eastern Finn Cattle; ERI, Eringer; EVO, Evolenard; HFR, Holstein Friesian; GAL, Galloway; HGY, Hungarian Grey; ICL, Icelandic; JER, Jersey; JUT, Jutland; LIM, Limousin; MBE, Montbéliard; MCG, Marchigiana; MEN, Minorcan (Menorquina); MMA, Maremmana; MOD, Modicana; NOR, Normande; PIM, Piemontese; PIS, Mucca Pisana; POD, Podolica; POR, Polish Red; PRI, Italian Red Pied (Pezzata Rossa Italiana); REN, Rendena; RGA, Galician Blond (Rubia Gallega); ROM, Romagnola; SAY, Sayaguesa; SIM, Simmental; SRP, Swedish Red-Polled; SWB, Swiss Brown; TDL, Fighting Cattle (Toro de Lidia); TEM, Telemark; TUD, Tudanca; VPR, Aosta Red Pied (Valdostana Pezzata Rossa); WRP, Western Red Polled. AYR and HFR have been sampled outside their region of origin. 
indicated that 13 Betizu animals from the same location were similar to animals from two other locations, but highly inbred. As this confounded the clustering and distance plots, this inbred Betizu subpopulation was excluded from the analyses.

\section{Molecular analysis}

Genotyping of the AFLPs was carried out as described previously with the enzymes ECORI and TAQI and the primer combinations E35-T32, E39-T33 and E45-T32 (AjmoneMarsan et al. 1997) using a commercial service (Keygene) or in the Piacenza Laboratory (Table S1). Genotyping of the 30 microsatellite loci recommended by the Food and Agriculture Organization for genetic diversity studies (http:// dad.fao.org/en/refer/library/guidelin/marker.pdf) was carried out by commercial service (Labogena, France) or by the laboratories that carried out the sampling (Table S1). Additional genotypes of a subset of 19 microsatellite loci for a number of Asian and Italian breeds are from Loftus et al. (1999) and Cymbron et al. (2005).

Model-based clustering (Pritchard et al. 2000) was carried out using the STRUCTURE program (http:// pritch.bsd.uchicago.edu/structure.html). As recommended in the program documentation for dominant genotypes, the no-admixture ancestry model was used, which yielded the best differentiation in combination with independent allele frequencies. Alternative models gave very similar results with only slightly reduced differentiation of clusters. For most runs, 20000 burn-ins were followed by 50000 iterations. This gave reproducible patterns, which were not improved by longer runs. The output of stRUCTURE was visualized by the DISTRUCT program (www-hto.usc.edu/ $\sim$ noahr/distruct.html ).

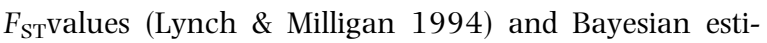
mates of Nei's standard $\left(D_{s}\right)$ and Reynolds $\left(D_{\mathrm{R}}\right)$ genetic distances between breeds or clusters of breeds were calculated on the basis of non-uniform prior distribution of allele frequencies using the AFLPsurv program (Vekemans 2002, http://www.ulb.ac.be/sciences/lagev/aflp-surv.html). NeighborNet graphs (Bryant \& Moulton 2004) based on $\mathrm{D}_{\mathrm{s}}$ distances were constructed with the SplitsTree program (http:// www.splitstree.org). Average values of the Jaccard bandsharing index were calculated with the program POPDIST (A. Valentini, Viterbo).

\section{Results}

\section{Genotyping and combination of data sets}

Three enzyme-primer combinations were selected that optimally displayed polymorphisms in the cattle genome (Ajmone-Marsan et al. 1997). Analysis in the Keygene and Piacenza laboratories gave 115 and 143 polymorphic AFLP fragments respectively. The size range that could be scored in both laboratories contained 81 unambiguous polymorphic bands and 163 monomorphic bands.

The correspondence between data sets was tested by typing five breeds in both laboratories and by independent sampling and fingerprinting of French and Italian populations of Limousin cattle. An error rate of $2 \%$ in the 81 common markers was found for 162 Italian samples genotyped in duplicate, which is considered typical for AFLPbased population genetic studies (Bonin et al. 2004; Gorni et al. 2004). Genetic distances between European taurine breeds were in the range of $0.008-0.040$, but were 0.00005 or less for the same breed analyzed in two laboratories and 0.0035 between the French and Italian Limousin populations.

Twenty-two randomly selected animals per breed were included in the analysis by model-based clustering in order to avoid a bias towards over-represented breeds.

\section{Genetic subdivision}

Values for the fixation index $\left(F_{\mathrm{ST}}\right)$ on the basis of dominant data (Lynch \& Milligan 1994) were estimated to be 0.15 for

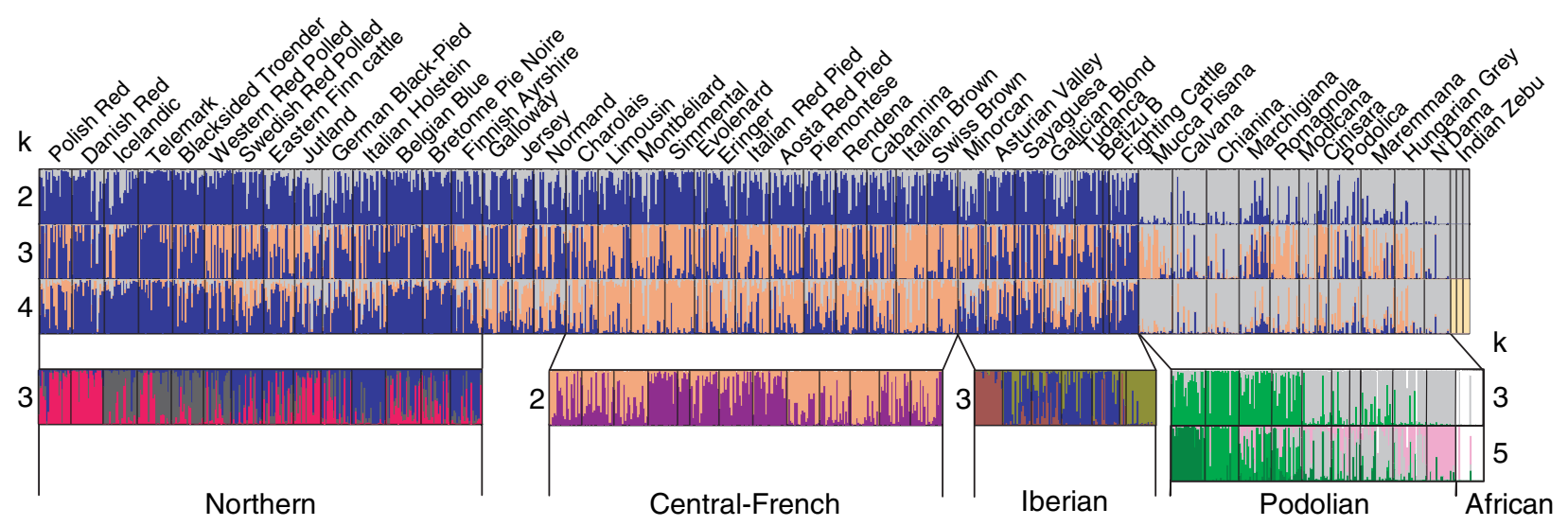

Figure 2 Model-based clustering of AFLP fingerprints from all 51 breeds or from regional subsets of breeds. Individuals are represented by lines, the colors of which indicate the likelihood of belonging to one of the $k$ inferred clusters. 
the complete data set, 0.099 within Europe and slightly lower (0.089) within Europe excluding the Podolian breeds. Genetic subdivision was further analyzed by model-based clustering (Pritchard et al. 2000) testing several numbers of clusters $(k)$.

Analysis at $k=2$ separated Indian zebu, African N'Dama, Italian and Hungarian Podolian cattle from other European breeds (Fig. 2). Incomplete differentiation at $k=3$ and $k=4$ suggested a separate cluster of French and Alpine breeds with intermediate positions for Jersey, Galloway and Normande. Indian zebu breeds were differentiated from African and Podolian cattle at $k=4$. In a data set in which the number of European and African animals was reduced to 62 individuals (data not shown), the first split at $k=2$ was between zebu and taurine, followed at $k=3$ by a split between European and African animals. This indicates that the clustering inferred at $k=2$ and $k=3$ in the complete data set was influenced by the under-representation of Indian and African cattle.

Although the likelihood of the data increased steadily with $k$-values from 2 to $10, k$ values higher than 4 did not detect additional clusters of breeds (not shown). However, a further subdivision was suggested by analyzing separately the breeds from different regions (Fig. 2). Within the Northern breeds, Danish and Polish Red cattle as well as Nordic cattle tended to form separate clusters. Likewise, a cluster within the French-Alpine group is formed by the spotted Simmental-like cattle (Fleckvieh breeds) together with the Southern Swiss Evolenard and Eringer, but excluding the French Montbéliard. In Iberian cattle, the inbred Minorcan breed and fighting bulls were separated from other breeds. Analysis of Podolian and African breeds generated clusters for African cattle, the Pisana, the Chianina with the closely related Calvana and the Hungarian Grey respectively.

\section{Genetic distances}

We choose the Nei standard genetic distance $D_{s}$ because of its linearity with divergence time (Laval et al. 2002). Comparison of $D_{s}$ values with the average across-breed values of the Jaccard index of AFLP band sharing of individuals showed a good correlation (Fig. 3a), indicating that $D_{s}$ also measures the sequence divergence between breeds. In contrast, Reynolds distances, which are recommended as measure for the divergence of closely related populations (Laval et al. 2002), were only colinear with the Jaccard values for taurine breeds.

As shown in Fig. $3 \mathrm{~b}$ for taurine breeds, the $D_{s}$ values were five to seven times higher than $D_{s}$ values calculated from microsatellite data (European Cattle Genetic Diversity Consortium 2006). However, genotypes for 19 microsatellite markers from zebu breeds (MacHugh et al. 1997; Freeman et al. 2006) a lower ratio of microsatellite- and ALFP-based $D_{s}$ distances in a comparison of taurine to zebu breeds (4.2-4.5,
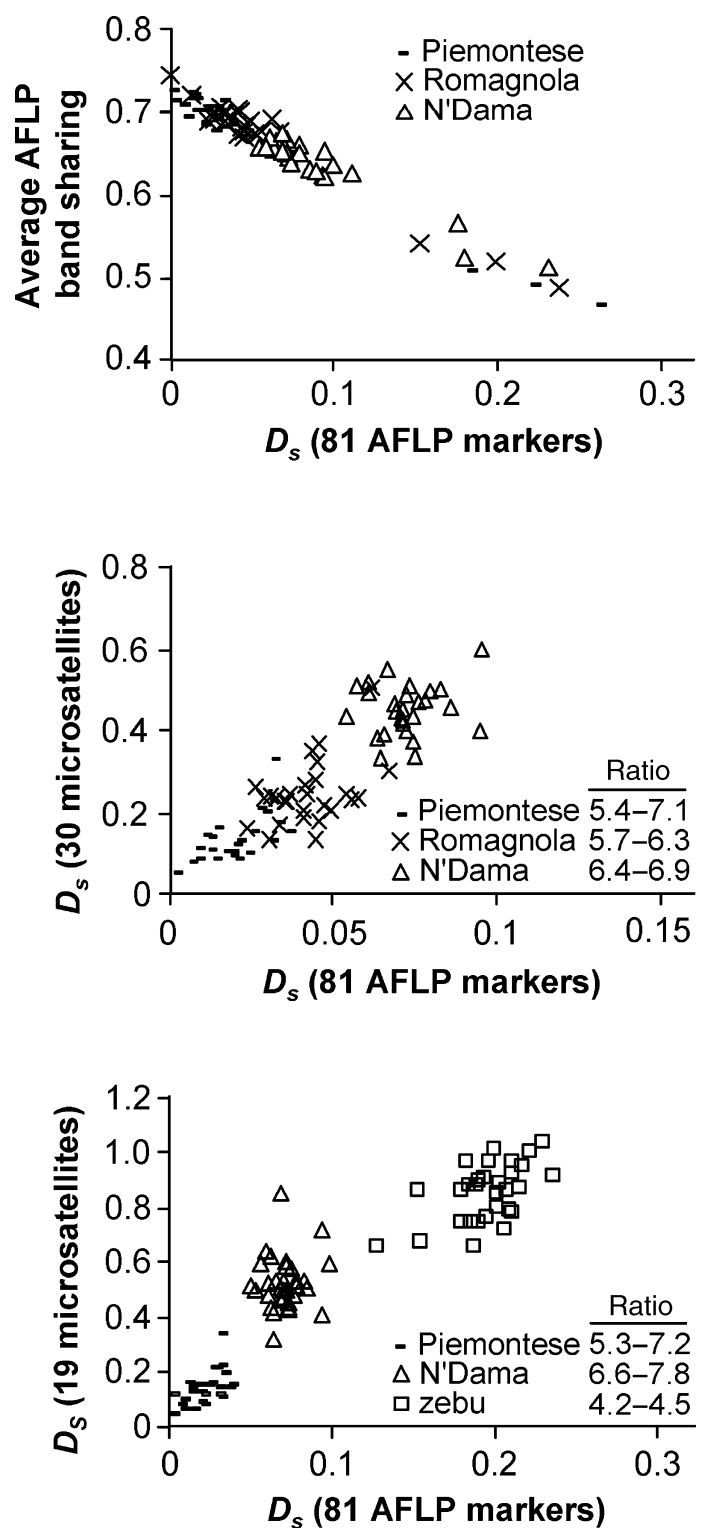

Figure 3 Genetic distances between breeds derived from ALFP data. (a) Nei's standard distance $D_{s}$ between the indicated breed and other breeds against average across-breed Jaccard index of band sharing. Monomorphic bands have not been taken into account. (b) $D_{s}$ distances between the indicated breeds and other breeds against the corresponding distance on the basis of 30 microsatellites. (c) $D_{s}$ distances between the indicated taurine breeds and zebu respectively and all other breeds plotted against the corresponding distance on the basis of 19 microsatellites. The range of ratios of the AFLP- and microsatellitebased distances indicates the central $90 \%$ confidence interval as calculated by linear regression.

Fig. 3c), presumably because of a saturation of the microsatellite-based distance after longer periods of divergence.

This difference between markers was also apparent from a visualization of the $D_{s}$ distances of regional groups of breeds in NeighborNet graphs (Fig. 4). These graphs visualize conflicting tree topologies that may correspond to reticulated relationships of interacting populations (Bryant \& 


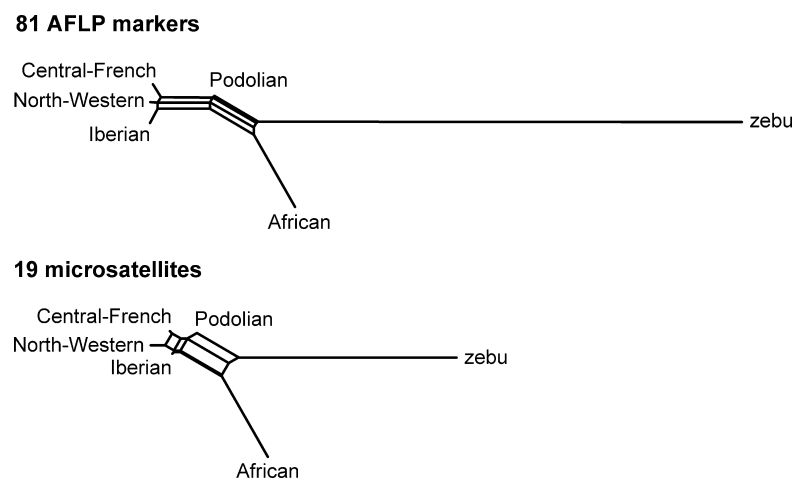

Figure 4 NeighborNet graphs of $D_{s}$ distances for groups of breeds analysed by AFLP fingerprinting or by typing with 19 microsatellites (see Table S1).

Moulton 2004). Podolian cattle were positioned between the African N'Dama and the zebus on the basis of AFLP data, while microsatellite-based distances clustered all European cattle together.

\section{Discussion}

In an earlier study, we showed that AFLPs can be used to compare related bovine species (Buntjer et al. 2002) and bovine breeds (Ajmone-Marsan et al. 2002; Negrini et al. 2006). The results of the present study indicate that for assessing genetic diversity, AFLP markers contribute information that is complementary to microsatellite marker data (cf. Gaudeul et al. 2004; Foulley et al. 2006; SanCristobal et al. 2006). In a separate study (unpublished results), we found that model-based clustering of microsatellite genotypes differentiated several cattle breeds or breed groups from northern and western Europe at lower $k$-values than Mediterranean breed groups. In contrast, the AFLP data set used here discriminated Podolian from other European cattle at $k=2$ and only partially differentiated northern and western breeds. Genetic distances between taurine and indicine breeds based on microsatellite allele frequencies were relatively short (Fig. 3c, Fig. 4). These observations indicate that, relative to microsatellite variation, AFLP emphasizes the differentiation between zebu and taurine cattle and between taurine breeds from Eastern and European origin. Because most variation in AFLP fingerprints corresponds to SNPs or indels, our study predicts that a European-wide SNP analysis will highlight the Eastern component in Podolian cattle and the separate position of the Alpine-French breeds.

Principal coordinate analysis of European breeds (results not shown) reproduced only the separation of Podolian and non-Podolian European breeds. Model-based clustering (Pritchard et al. 2000) reconstructed subdivisions based on individual genotypes and potentially detected clusters of related breeds or introgression events. This approach has been used for clustering of microsatellite genotypes of chicken (Rosenberg et al. 2001) and goat
(Cañón et al. 2006) breeds and to simulated AFLP data (Evanno et al. 2005). One caveat is that the inferred clusters depend not only on the divergence of populations, but also on the composition of the data set. In this study, zebu breeds formed a separate cluster only at $k=4$ because of their numerical under-representation. Conversely, inclusion in the data set of 45 additional Maremmana animals led to the identification of a separate cluster for this breed.

Although the differentiation of the non-Podolian European breeds with the current data set was incomplete, the suggested clusters correlated with the geographical origin: the Danish and Polish Red cattle from the Baltic region, Nordic cattle, a larger group of breeds from France and the Alpine regions, and within this group a cluster of Simmental-like breeds and two Southern Swiss breeds. Within Iberian and Podolic cattle, separate clusters were defined for the inbred Minorcan, Fighting cattle and Pisana (derived from a cross of Chianina and Swiss Brown) breeds and for the Hungarian Grey cattle.

The clustering of the Alpine and French breeds indicates a shared history, possibly the legacy of genetic bottlenecks in the Alpine valleys during the spreading of domestic cattle to the West.

Model-based clustering as well as networks based on genetic distances indicated an influence of Eastern cattle in the Italian and Hungarian Podolian breeds, confirming earlier results based on biochemical data (Baker \& Manwell 1980; Medjugorac et al. 1994; Pieragostini et al. 2000). Because it is unlikely that there were frequent contacts between European taurine and indicine or other Eastern cattle, the most realistic scenario is a gene flow via MiddleEastern and Balkan breeds (Beja-Pereira et al. 2006). Grey steppe breeds have been kept from the 12th century on the plains north-west of the Black Sea (Felius 1995) and have presumably a more Eastern origin. However, Chianina cattle are supposed to descend from large white cattle already described in texts from the Roman era (Negrini et al. 2006). Mitochondrial haplotypes also suggest introgression of aurochs in Italian cattle (Beja-Pereira et al. 2006). Middle-Eastern cattle may have been brought to imperial Rome as tributes (Pieragostini et al. 2000), but probably not in substantial numbers. Later introgression may have occurred during migrations or invasions of the Visigoths and Huns (Alderson 1992; Felius 1995) and by trade in the 14th and 15th centuries (Felius 1995). Thus several historic events and processes may have contributed to the high genetic diversity of Italian cattle, which also harbors several distinct Alpine breeds and the composite Piemontese (Felius 1995).

\section{Acknowledgements}

This work has been supported by the European Commission (project RESGEN $\mathrm{N}^{\circ}$ CT98-118), the Nordic Council of 
Ministers and the Nordic Gene Bank for Farm Animals (NGH). The content of this publication does not represent the views of the European Commission or its services.

\section{References}

Ajmone-Marsan P., Valentini A., Cassandro M., Vecchiotti-Antaldi G., Bertoni G. \& Kuiper M. (1997) AFLP markers for DNA fingerprinting in cattle. Animal Genetics 28, 418-26.

Ajmone-Marsan P.R. Negrini R., Milanesi E., Bozzi R., Nijman I.J., Buntjer J.B., Valentini A. \& Lenstra J.A. (2002) Genetic distances within and across cattle breeds as indicated by biallelic AFLP markers. Animal Genetics 33, 280-6.

Alderson L. (1992) The categorisation of types and breeds of cattle in Europe. Archivos de Zootecnia 41, 325-34.

Baker C.M. \& Manwell C. (1980) Chemical classification of cattle. 1. Breed groups. Animal Blood Groups and Biochemical Genetics 11, 127-50.

Beja-Pereira A., Caramelli D., Lalueza-Fox C. et al. (2006) The origin of European cattle: Evidence from modern and ancient DNA. Proceedings of the National Academy of Sciences of the United States of America 21, 8113-8.

Bensch S. \& Åkesson M. (2005) Ten years of AFLP in ecology and evolution: why so few animals? Molecular Ecology 14, 2899-914.

Bonin A., Bellemain E., Bronken Eidesen P., Pompanon F., Brochmann C. \& Taberlet P. (2004) How to track and assess genotyping errors in population genetics studies. Molecular Ecology 13, 3261-73.

Bradley D.G., MacHugh D.E., Loftus R.T., Sow R.S., Hoste C.H. \& Cunningham E.P. (1994) Zebu-taurine variation in Y chromosomal DNA: a sensitive assay for genetic introgression in West African trypanotolerant cattle populations. Animal Genetics 25, 7-12.

Bradley D.G., MacHugh D.E., Cunningham P. \& Loftus R.T. (1996) Mitochondrial diversity and the origins of African and European cattle. Proceedings of the National Academy of Sciences USA 93, 5131-5.

Bruford M.W., Bradley D.G. \& Luikart G. (2003) DNA markers reveal the complexity of livestock domestication. Nature Reviews Genetics 4, 900-10.

Bryant D. \& Moulton V. (2004) Neighbor-net: an agglomerative method for the construction of phylogenetic networks. Molecular Biology and Evolution 21, 255-65.

Buntjer J.B., Otsen M., Nijman I.J., Kuipers M.T.R. \& Lenstra J.A. (2002) Phylogeny of bovine species based on AFLP fingerprinting. Heredity 89, 46-51.

Cañón J., Alexandrino P., Bessa I. et al. (2001) Genetic diversity measures of local European beef cattle breeds for conservation purposes. Genetics Selection Evolution 33, 311-32.

Cañón J., García D., García-Atance M.A., Obexer-Ruff G., Lenstra J.A., Ajmone-Marsan P., Dunner S. and the ECONOGENE Consortium (2006) Geographical partitioning of goat diversity in Europe and the Middle East. Animal Genetics 37, 327-34.

Cymbron T., Freeman A.R., Isabel Malheiro M., Vigne J.D. \& Bradley D.G. (2005) Microsatellite diversity suggests different histories for Mediterranean and Northern European cattle populations 2005. Proceedings - Royal Society of London. Biological Sciences 272, 1837-43.

Del Bo L., Polli M., Longeri M., Ceriotti G., Looft C., Barre-Dirie A., Dolf G. \& Zanotti M. (2001) Genetic diversity among some cattle breeds in the Alpine area. Journal of Animal Breeding and Genetics 118, 317-25.

European Cattle Genetic Diversity Consortium (2006) Markerassisted conservation of European cattle breeds: an evaluation. Animal Genetics 37, 475-481.

Evanno G., Regnaut S. \& Goudet J. (2005) Detecting the number of clusters of individuals using the software STRUCTURE: a simulation study. Molecular Ecology 14, 2611-20.

Felius M. (1995) Cattle breeds. An Encyclopedia. Misset, Doetinchem, The Netherlands.

Foulley J.L., van Schriek M.G., Alderson L. et al. (2006) Genetic diversity analysis using lowly polymorphic dominant markers: the example of AFLP in pigs. Jouirnal of Heredity 97, 24452.

Freeman A.R., Meghen C.M., Machugh D.E., Loftus R.T., Achukwi M.D., Bado A., Sauveroche B. \& Bradley D.G. (2004) Admixture and diversity in West African cattle populations. Molecular Ecology 13, 3477-87.

Freeman A.R., Bradley D.G., Nagda S., Gibson J.P. \& Hanotte O. (2006) Combination of multiple microsatellite data sets to investigate genetic diversity and admixture of domestic cattle. Animal Genetics 37, 1-9.

Gaudeul M., Till-Bottraud F., Barjon I. \& Manel S. (2004) Genetic diversity and differentiation in Eryngium alpinum L. (Apiaceae): comparison of AFLP and microsatellite markers. Heredity 92, 508-18.

Gorni C., Williams J.L., Heuven H.C. et al. (2004). Application of AFLP ${ }^{\circledR}$ technology to radiation hybrid mapping. Chromosome Research 12, 1-13.

Hall S.J.G. (2004) Livestock Biodiversity. Genetic Resources for the Farming of the Future. Blackwell Publishing, Oxford.

Hanotte O., Bradley D.G., Ochieng J.W., Verjee Y., Hill E.W. \& Rege J.E. (2002) African pastoralism: genetic imprints of origins and migrations. Science 296, 336-9.

Ibeagha-Awemu E.M., Jann O., Weimann C. \& Erhardt G. (2004) Genetic diversity, introgression and relationships among West/ Central African cattle breeds. Genetics Selection Evolution 36, 673-90.

Kantanen J., Olsaker I., Holm L.E., Lien S., Vilkki J., Brusgaard K., Eythorsdottir E., Danell B. \& Adalsteinsson S. (2000) Genetic diversity and population structure of 20 North European cattle breeds. Journal of Heredity 91, 446-574.

Kumar P., Freeman A.R., Loftus R.T., Gaillard C., Fuller D.Q. \& Bradley D.G. (2003) Admixture analysis of South Asian cattle. Heredity 91, 43-50.

Laval G., SanCristobal M. \& Chevalet C. (2002) Measuring genetic distances between breeds: use of some distances in various short term evolution models. Genetics, Selection and Evolution 34, 481507.

Loftus R.T., MacHugh D.E., Ngere L.O., Balain D.S., Badi A.M., Bradley D.G. \& Cunningham E. P. (1994) Mitochondrial genetic variation in European, African and Indian cattle populations. Animal Genetics 25, 265-71.

Loftus R.T., Ertugrul O., Harba A.H., El-Barody M.A., MacHugh D.E., Park S.D. \& Bradley D.G. (1999) A microsatellite survey of cattle from a centre of origin: the Near East. Molecular Ecology 8, 2015-22.

Lynch M. \& Milligan B.G. (1994) Analysis of population genetic structure with RAPD markers. Molecular Ecology 3, 91-9. 
MacHugh D.E., Shriver M.D., Loftus R.T., Cunningham P. \& Bradley D.G. (1997) Microsatellite DNA variation and the evolution, domestication and phylogeography of taurine and zebu cattle (Bos taurus and Bos indicus). Genetics 146, 1071-86.

Martín-Burriel I., Garcia-Muro E. \& Zaragoza P. (1999) Genetic diversity analysis of six Spanish native cattle breeds using microsatellites. Animal Genetics 30, 177-82.

Medjugorac I., Kustermann W., Lazar P., Russ I. \& Pirchner F. (1994) Marker-derived phylogeny of European cattle supports demic expansion of agriculture. Animal Genetics 25 (Suppl. 1), 19-27.

Moazami-Goudarzi K., Laloë D., Furet J.P. \& Grosclaude F. (1997) Analysis of genetic relationships between 20 cattle breeds with 17 microsatellites. Animal Genetics 28, 338-45.

Moazami-Goudarzi K., Belemsaga D.M.A., Ceriotti G. et al. (2001) Caractérisation de la race bovine Somba à l'aide de marqueures moléculaires. Revue d'Élevage et de Médicine Vétérinaire dans des Pays Tropicaux 54, 129-38.

Negrini, R., Milanesi E., Bozzi R., Pellecchia M. \& Ajmone-Marsan P. (2006) Tuscany autochthonous cattle breeds: an original genetic resource investigated by AFLP markers. Journal of Animal Breeding and Genetics 123, 10-6.

Peelman L.J., Mortiaux F., Van Zeveren A., Dansercoer A., Mommens G., Coopman F., Bouquet Y., Burny A., Renaville R., Portetelle D. (1998) Evaluation of the genetic variability of 23 bovine microsatellite markers in four Belgian cattle breeds. Animal Genetics 29, 161-167.

Pieragostini E., Scaloni A., Rullo R. \& Di Luccia A. (2000) Identical marker alleles in Podolic cattle (Bos taurus) and Indian zebu (Bos indicus). Comparative Biochemistry and Physiology Part B 127, 1-9.

Pritchard J.K., Stephens M., Donnelly P. (2000) Inference of population structure using multilocus genotype data. Genetics $\mathbf{1 5 5}$, 945-59.

Rosenberg N.A., Burke T., Elo K. et al. (2001) Empirical evaluation of genetic clustering methods using multilocus genotypes from 20 chicken breeds. Genetics 159, 699-713.

Ruane J. (1999) A critical review of the value of genetic distance studies in conservation of animal genetic resources. Journal of Animal Breeding and Genetics 116, 317-23.

SanCristobal M., Chevalet C., Peleman J. et al. (2006) Genetic diversity in European pigs utilizing amplified fragment length polymorphism markers. Animal Genetics 37, 232-8.

Schmid M., Saitbekova N., Gaillard C. \& Dolf G. (1999) Genetic diversity in Swiss cattle breeds. Journal of Animal Breeding and Genetics 116, 1-8.
Vekemans X. (2002) AFLP-SURV version 1.O. Laboratoire de Génétique et Ecologie Végétale, Université Libre de Bruxelles, Belgium.

Wiener P., Burton D. \& William J.L., (2004) Breed relationships and definition in British cattle: a genetic analysis. Heredity 93, 597602.

\section{Appendix 1.}

The following members of the European Cattle Genetic Diversity Consortium contributed to this work:

D. Laloë, Station de Génétique Quantitative et Appliquée, INRA, Jouy-en-Josas, France; P. Wiener, D. Burton, Roslin Institute, UK; C. Weimann, Justus-Liebig Universität, Giessen, Germany; B. Harlizius, A. Barre-Dirie, A. Mengers, School of Veterinary Medicine, Hannover, Germany; C. Looft, E. Kalm, Christian-Albrechts-Universität, Kiel, Germany; J. Cañón, Universidad Complutense de Madrid, Spain; P. Zaragoza, I. Martín-Burriel, Veterinary Faculty, Zaragoza, Spain; A. Sanchez, Universitat Autonoma de Barcelona; M.C. Savarese, C. Marchitelli, Università della Tuscia, Viterbo, Italy; M. Zanotti, Università degli Studi di Milano, Italy; F. Pilla, A. Bruzzone, D. Iamartino, Università del Molise, Campobasso, Italy; A.R. Freeman, Trinity College, Dublin, Ireland; L.E. Holm, Danish Institute of Agricultural Sciences, Tjele, Denmark; E. Eythorsdottir, Agricultural Research Institute, Reykjavik, Iceland; G. Mommens, Dr. Van Haeringen Polygen, Malle, Belgium; G. Dolf, University of Berne, Switzerland; M. Felius, Rotterdam, The Netherlands.

\section{Supplementary material}

The following supplementary material is available for this article online from http://www.blackwell-synergy.com/doi/ full/10.1111/j.1365-2052.2007.01554.x

Table S1 Breeds analyzed by AFLP fingerprinting.

Please note: Blackwell Publishing is not responsible for the content or functionality of any supplementary materials supplied by the authors. 